\title{
QUESTÕES TEÓRICO-METODOLÓGICAS PARA O "TRABALHO SOCIAL" NA EXTENSÃO RURAL: DESAFIOS PARA ECONOMISTAS DOMÉSTICOS E ASSISTENTES SOCIAIS
}

\section{THEORETICAL-METHODOLOGICAL CHALLENGES FOR THE SOCIAL WELFARE EXTENSIONISTS PERFORMANCE}

\author{
José Carlos do Amaral Junior ${ }^{1}$
}

\section{Resumo}

Este trabalho objetivou analisar de que forma o "trabalho na área social" se desenvolve na extensão rural atual, considerando-se as trajetórias, as rupturas, as inconstâncias e apreendendo quais são os desafios teórico-metodológicos postos pelas condições concretas a esses profissionais. A discussão foi conduzida pelo método materialista histórico-dialético, buscando pontuar, segundo o campo empírico da extensão rural pública paranaense, quais eram os principais elementos em torno da prática de Economistas Domésticos e Assistentes Sociais extensionistas. Por meio de uma pesquisa bibliográfico-documental percebeu-se que, para a realidade analisada, predomina uma indefinição de papeis das distintas áreas de conhecimento/formação profissional, em função de um hibridismo dos modelos historicamente assumidos pela extensão rural, da baixa prevalência histórica desses profissionais nas agências de extensão e de questões pertinentes ao processo de formação histórico de cada profissão. Além disso, percebeu-se uma inversão na forma de organização do trabalho para a área, com predominância de ações pontuais em detrimento de planejamentos estruturados a partir dos fenômenos sociais identificados. Verificou-se, ainda, que os desafios teórico-metodológicos apresentados também precisam ser superados, sob a ótica de entendimento dos objetos específicos de cada área/formação profissional, compreendendo como se relacionam com os fenômenos apresentados como prioritários para a intervenção da prática extensionista.

Palavras-chave: Extensão Rural. Economia Doméstica. Serviço Social. Bem-estar social

\begin{abstract}
This work aimed to analyze how "work in the social area" develops in the current rural extension considering the trajectories, the ruptures, the inconsistencies and apprehending what are the theoretical and methodological challenges posed by the concrete conditions to these professionals. Thus, a discussion conducted by the historical-dialectical materialist method was elaborated, seeking to demonstrate, according to the empirical field of Paraná's public rural extension, which were the main elements around the practice of Home Economists and Social Workers extensionists. It can be seen, through a documentary bibliographic research that, for the context, there is a predominance of undefined roles of different areas of knowledge/professions, due to a hybridism of the models historically assumed by rural extension, the low historical prevalence of these professionals in extension agencies and questions relevant to the historical formation process of each area. In addition, there was a reversal in the form of work organization for the area, with a predominance of specific actions to the detriment of structured planning based on the identified social phenomena. What can be provisionally identified is that the theoreticalmethodological challenges presented also need to be overcome from the perspective of understanding the specific objects of each area/profession, understanding how they relate to the phenomena presented as priorities for the intervention of extension practice.
\end{abstract}

Key-words: Rural extension. Home Economics. Social work. Social welfare.

\footnotetext{
${ }^{1}$ Doutorando do Programa de Pós-Graduação em Memória: Linguagem e Sociedade da Universidade Estadual do Sudoeste da Bahia (UESB). Economista Doméstico no Instituto Paranaense de Assistência Técnica e Extensão Rural (EMATER-PR).
} 


\section{INTRODUÇÃO}

A extensão rural faz parte da vida dos brasileiros há mais de 70 anos em seu formato de Política de Estado. A primeira iniciativa se deu em 1948, no estado de Minas Gerais, enquanto uma parceria público-privada entre instituições de cunho privado dos EUA e o governo brasileiro, a Associação de Crédito e Assistência Rural de Minas Gerais (ACAR-MG) (PEIXOTO, 2008). Via de regra, a extensão rural - frequentemente referendada também pela sigla ATER, que designa Assistência Técnica e Extensão Rural - é definida como um processo de educação não formal que ocorre entre um componente técnico (geralmente a equipe de técnicos especializados) e o agricultor. Como demonstra Caporal (1991), o conceito de extensão rural, longe de ser consensual, quase sempre remete a uma relação horizontal entre essas duas partes, elementos herdados de uma crítica direta estabelecida por Paulo Freire em “Extensão ou Comunicação?” (2018) à prática extensionista verticalizada comum no Brasil nas décadas de 1960 e 1970.

A extensão rural, portanto, pode ser entendida como uma Política de Estado, um fenômeno educativo e uma prática profissional. Enquanto Política de Estado, está representada pela ATER pública oficial que, desde o final da década de 1940, assumiu diversas conformações dentro do aparelho estatal (PEIXOTO, 2008). Enquanto fenômeno educativo, enquadra-se no que Cury (1989) preconiza como instituição pedagógica, a qual se realiza pela via da educação não formal, pois sua principal linha de efetivação se dá na construção de processos educativos instaurados entre uma equipe técnica e um determinado público alvo que não se delimitam ao ambiente escolar e não estão abrangidos pelo sistema formal oficial de ensino $^{3}$. Por último, é uma prática profissional na medida em que estabelece diretrizes específicas para a "ação extensionista”, na qual engenheiros agrônomos, médicos veterinários, economistas domésticos, assistentes sociais e outros profissionais se convertem cotidianamente em extensionistas por se tornarem agentes pedagógicos da extensão rural.

Historicamente, no entanto, essa instituição pedagógica passou por modelos distintos a partir do qual ideológica e metodologicamente se efetivou. Segundo Rodrigues (1997), são três modelos principais que marcam a trajetória histórica da extensão rural brasileira: o humanismo assistencialista, o difusionismo-produtivista e o humanismo crítico. O primeiro modelo remonta à época de implementação da extensão rural no país, cuja Política de Estado foi amplamente

\footnotetext{
${ }^{2} \mathrm{O}$ trabalho foi originalmente publicado em 1969.

${ }^{3}$ Características fundamentais para classificação do processo de educação formal, conforme exposto por Maria da Glória Gohn (2006).
} 
elaborada para promover modificações de hábitos e comportamentos da população do campo. Um dos principais entraves do desenvolvimento era o considerado atraso econômico, produtivo e cultural dessa população, para a qual a extensão rural inicialmente se orientou enquanto vetor de modificação (FONSECA, 1985). Dessa maneira, a extensão rural se efetivou nesse modelo por intermédio de uma equipe paritária, geralmente composta por um agrônomo ou técnico agrícola e por uma economista doméstica ou técnica em economia doméstica (PINHEIRO, 2016). Essa divisão, longe de ser ocasional, representa certa divisão sexual do trabalho em bases funcionalistas, para a qual a mulher se destinava vocacionalmente ao ambiente doméstico e o homem, ao mundo da produção (LOPES, 1995).

Esse primeiro modelo consagrou o lema "um agrônomo, uma professora e um jipe", resumindo toda a pretensão desenvolvimentista que a extensão rural trazia baseada no modelo estadunidense (FONSECA, 1985). Foi esse primeiro modelo também que, de forma geral, promoveu uma divisão interna nas agências de ATER entre uma "área produtiva" e uma área de "bem-estar social" - dicotomia alinhada aos princípios gerais do humanismo assistencialista que reproduzia. O modelo humanista assistencialista marcou a identidade da ATER brasileira, destacando seu primeiro momento como uma das poucas políticas que alcançava a população do campo, historicamente desassistida. Esse formato de extensão rural, no entanto, seria reformulado a partir da década de 1960.

O segundo modelo, difusionista-produtivista, foi implantado a partir da Ditadura Militar, governo instaurado após o Golpe de 1964, tendo como foco a transferência de tecnologias e o aumento da produção para gerar supersafras (RODRIGUES, 1997). Dessa maneira, extirpou lentamente as ações e profissionais da área de "bem-estar social" das agências de ATER sem, contudo, extingui-la. Pinheiro (2016) demonstra como o quadro da "área produtiva" cresceu exponencialmente enquanto o quadro da "área de bem-estar social" tendeu a estagnar a partir da década de 1960. Esse modelo de ATER foi impulsionado pela Revolução Verde ${ }^{4}$, pela percepção de desenvolvimento econômico do Governo Militar e pela adoção das commodities (PEIXOTO, 2008).

Já no terceiro modelo, que se configura mais como um projeto em aberto do que concretizado, prevalece o humanismo crítico. Suas bases foram formuladas a partir da exaustão dos elementos do modelo difusionista-produtivista, que passou a ser questionado frente às crises econômicas das décadas de 1970 e 1980 e às pressões dos movimentos da sociedade civil (RODRIGUES, 1997). Sua premissa básica estava dada na reformulação da

\footnotetext{
${ }^{4}$ A Revolução Verde pode ser entendida como um processo de avanço técnico-científico sobre as formas de produção agrícola, amplamente impulsionado por investimentos de grupos específicos dos países centrais da produção capitalista, sob o pretexto de combate à fome (ANDRADES; GANIMI, 2007).
} 
ATER para um processo dialógico e horizontal, superando a transferência verticalizada de conhecimentos e tecnologias amplamente adotada, buscando, também, reorientar o processo de extensão rural para moldes participativos, comunitários e destinado também aos públicos minoritários. Esse modelo, longe de ter se esgotado, não chegou a lograr grande êxito. Representou avanços - como a reordenação da ATER para o agricultor familiar e a aprovação da Política Nacional de Assistência Técnica e Extensão Rural (PNATER) pela Lei no 12.188 de 11 de janeiro de 2010 - mas também ficou limitado por retrocessos - como o fim da Empresa Brasileira de Assistência Técnica e Extensão Rural (EMBRATER) no início da década de 1990 (PEIXOTO, 2008).

Nessa trajetória, a "área de bem-estar social”, atualmente designada também apenas como "área social", apresentou inconstâncias que são importantes para se compreender a configuração da ATER nos dias atuais. Primeiro, foi implantada sob o modelo humanista assistencialista, marcado pelo fatalismo, pelo positivismo e pelas intervenções orientadas massivamente pelas mudanças de hábitos e comportamentos considerados atrasados e indesejáveis (RODRIGUES, 1997). Segundo, foi amplamente extirpada das instituições de ATER no modelo difusionista-produtivista, restando apenas elementos que podem ser considerados vestígios da prática humanista assistencialista e outros que estavam mais alinhados à pauta produtivista. Em terceiro - e aqui reside a importância do problema da pesquisa - o modelo humanista crítico promove, implicitamente, uma retomada à área social na medida em que fomenta - com embasamento na PNATER - uma série de objetivos, prioridades e atividades que demandam profissionais específicos cuja formação esteja baseada na análise, intervenção e compreensão das relações e fenômenos sociais.

Portanto, este trabalho pretende analisar de que forma o "trabalho na área social" se desenvolve na extensão rural atual, considerando-se as trajetórias, as rupturas, as inconstâncias e apreendendo quais são os desafios teórico-metodológicos postos pelas condições concretas aos profissionais dessas áreas.

\section{CONSIDERAÇÕES SOBRE O MÉTODO}

O método elencado para a condução do trabalho foi o materialismo histórico-dialético, proposta construída no século XIX por Marx e Engels (2007), como uma forma de compreensão e transformação da realidade. O método se elenca, portanto, em torno de categorias centrais que são formuladas para auxiliar nesse movimento, garantindo a 
processualidade da construção teórica e da transformação da realidade. Dentre as principais categorias destacam-se a totalidade, o trabalho, a ideologia, a mediação e a dialética.

O materialista histórico-dialético não preconiza uma série de procedimentos e técnicas que devem ser aplicadas pelo pesquisador, mas uma posição do pesquisador diante do objeto e das questões epistemológicas postas (NETTO, 2011). Isso significa que, em termos de procedimentos e instrumentais, o pesquisador possa utilizar um conjunto bastante amplo e diverso, atendo-se, porém, às categorias estabelecidas para a condução materialista dialética do processo.

Ao analisar a extensão rural no Brasil, por exemplo, é indispensável o entendimento de sua inserção na totalidade de organização da sociedade. Dessa maneira, não se pode perder de vista os interesses dos EUA à época em promover uma ampla aproximação com os países periféricos, tanto para difundir o American Way Of Life quanto para impedir o avanço comunista e garantir a propagação dos modos de vida típicos do capitalismo monopolista (FONSECA, 1985). Também é preciso compreender a dimensão ideológica do objeto, entendendo que uma Política de Estado frequentemente reproduz os interesses das classes dominantes ${ }^{5}$, manifestando em suas distintas conformações essas nuances, o que explica as mudanças dos modelos extensionistas historicamente vivenciados (PINHEIRO, 2016). Além disso, os profissionais dos distintos campos de formação representam formas de "mediação" entre o conjunto de ideias que se intenta difundir e o público alvo no geral, devendo ser compreendidos somente nesse contexto de inserção. Assim, a escolha metodológica se expressa na medida em que a análise foi conduzida buscando construir esse movimento, em que os sujeitos e instituições não podem ser entendidos fora da história, da relação com a totalidade e do conjunto de relações sociais que constroem a sociedade.

Em termos de procedimentos, o estudo foi conduzido na forma de um ensaio teórico, por meio de documentos em fontes de domínio público, como aquelas disponibilizadas pela Agência Nacional de Assistência Técnica e Extensão Rural (ANATER) e pelo Instituto Paranaense de Assistência Técnica e Extensão Rural (EMATER-PR) - essa última instituição figurando como recorte empírico-analítico utilizado para condução objetiva da discussão proposta. A técnica utilizada, desse modo, foi a da pesquisa bibliográfico-documental que, conforme exposto por Gil (2008), consiste no levantamento em fontes primárias e secundárias segundo um recorte pré-estabelecido.

\footnotetext{
${ }^{5}$ A categoria ideologia está melhor apresentada em "A Idoelogia Alemã" (MARX; ENGELS, 2007), enquanto uma percepção "falseada" da realidade que não corresponde às relações reais dos fenômenos, mas uma reprodução ideal segundo o crivo do pensamento da classe dominante.
} 


\section{UMA RENOVAÇÃO?}

Em 2014, o estado do Paraná publicou edital de concurso público para o EMATER-PR ${ }^{6}$ (PARANÁ, 2014a), contemplando 56 vagas para a área social ${ }^{7}$, das quais 36 estavam destinadas aos profissionais do Serviço Social e 20 aos profissionais de Economia Doméstica. Importante ressaltar que esse foi o mesmo ano em que os cursos superiores de Economia Doméstica foram oficialmente extintos no país, fenômeno que se desenvolvia desde a década de 1980 e se agravou na segunda década dos anos 2000 (AMARAL JUNIOR, 2016).

Embora a instituição já possuísse Assistentes Sociais em seu quadro de funcionários, essa foi a primeira vez que um concurso público ou processo seletivo ${ }^{8}$ para a instituição abriu tantas vagas destinadas exclusivamente a esse perfil de formação. Para a Economia Doméstica, a instituição sempre abriu vagas em seus processos, mantendo historicamente a "tradição" de relacionar a formação com as atividades de extensão, o que, conforme demonstra Pinheiro (2016), longe de ser mero acaso, reforça uma relação funcionalista e pragmática embrionária de ambos os campos no Brasil.

A primeira leitura possível a partir desses dados é a de que o concurso de 2014 representa a primeira renovação expressiva do Instituto desde a década de 1990, refletindo as mudanças ocorridas nas últimas décadas e, buscando, por conseguinte, adequar o quadro de funcionários às exigências postas pelo novo arcabouço construído pela Política Pública, a PNATER. Isso explicaria a contratação, por exemplo, dos assistentes sociais, profissionais cujas conquistas corporativas das últimas décadas demarcaram reconhecido espaço na condução de políticas públicas e dentro do aparelho estatal.

A segunda leitura possível seria a de certo anacronismo na contratação dos Economistas Domésticos. Isso porque parece relativamente alheio ao processo decisório institucional que a formação seguia à época um intensificado curso generalizado de extinção que poderia resultar, inclusive, em baixa adesão ou não atendimento das vagas do certame $e$ que, em certa medida, ocorreu, ao se analisar a baixa concorrência ${ }^{9}$ para o cargo que, em

\footnotetext{
${ }^{6}$ A Empresa de Assistência Técnica e Extensão Rural do Paraná (EMATER-PR) se tornou Instituto Paranaense de Assistência Técnica e Extensão Rural em 2006, mantendo a sigla anterior. Em 2019, quando esse trabalho era finalizado, mudou oficialmente seu nome para Instituto de Desenvolvimento Rural do Paraná IAPAR-EMATER, motivo pelo qual optou-se por manter o nome anterior na tratativa aqui apresentada.

${ }^{7}$ Será utilizado esse termo para designar, genericamente, à área institucional composta por profissionais antes designados como pertencentes à área de "bem-estar social".

${ }^{8} \mathrm{O}$ Instituto possui quadro de funcionários misto, composto por estatutários e celetistas. Como historicamente também passou por distintas naturezas jurídicas, houve funcionários que ingressaram por concursos públicos e por processos seletivos.

${ }^{9}$ Segundo Edital $\mathrm{n} \cong 116 / 2014$ (PARANÁ, 2014b), o perfil profissiográfico é um documento oficial e publicado pelo estado do Paraná para estabelecer as atribuições de cada profissional que se insere no conjunto de trabalhadores
} 
alguns casos, chegou a registrar apenas um candidato por vaga. Isso demonstra a força da tradição que vincula à prática extensionista o tipo de formação recebida pelos Economistas Domésticos, marcada pelo tecnicismo, pelo positivismo, pelas influências tayloristas-fordistas e pela verticalidade na aplicação imediata (AMARAL JUNIOR, 2016).

Ao se analisar a descrição do perfil profissiográfico disponibilizado pelo Instituto ${ }^{10}$, percebe-se que há muita similaridade entre as descrições para ambas as profissões, com exceção de alguns componentes técnicos os quais são atribuições do Economista Doméstico e não se enquadram no escopo profissional do Serviço Social e vice-versa. Essa "diferenciação" está dada baseada em dois critérios centrais: os componentes técnicos que se referem à Economia Doméstica (alimentação, higiene, habitação, vestuário, entre outros) e o escopo de “cidadania” e Políticas Públicas para o Serviço Social. Apesar dessas diferenciações, prevalece uma estrutura descritiva de sobreposição e integração pouco detalhada, que pode ser interpretada como um conjunto de similaridades: articulação de políticas públicas, espaços participativos e deliberativos, garantias de direitos, e melhorias de condições de vida.

No geral, a similaridade parece indicar uma indefinição das atribuições específicas, posicionando ambos os profissionais em um arcabouço comum que, genericamente, poderia ser designado como "as atribuições do extensionista social". No entanto, essa aproximação é problemática. Analisando um cenário oposto, porém familiar, é possível perceber que, no perfil profissiográfico das profissões da área produtiva, os objetos são claramente posicionados: ao engenheiro agrônomo cabe os "processos de produção agropecuária e florestal" (EMATER, 2014), enquanto aos médicos veterinários competem "os aspectos relacionados às cadeias produtivas de criações do estado" (Op. cit.) e aos zootecnistas, "atividades de produção animal e de seus subprodutos e derivados" (Op. cit.). Assim, entende-se que "o objeto" da área social é pouco delimitado e, por consequência, essa ausência de delimitação se reflete nas atribuições profissionais específicas.

Mas por que essa ausência de delimitação do objeto prevalece para a área social, uma vez que se apresenta tão bem especificada para a área produtiva/econômica? Presume-se que é um resultado do próprio movimento histórico que envolveu a área e os profissionais de "bemestar social" dentro da instituição e, arrisca-se dizer, nacionalmente. Para compreender melhor como esse processo de ruptura e inconstâncias se estabeleceu, é preciso dar atenção especial a noção de fenômeno social e como ela se articula com a construção da "área" no bojo da prática extensionista.

do aparelho estatal. Dessa forma, estabelece institucionalmente o que é esperado de cada profissão, descrevendo suas atribuições específicas.

${ }^{10}$ Conforme Portaria no 020/2014 do EMATER-PR 


\section{O FENÔMENO SOCIAL ENQUANTO OBJETO DO “TRABALHO SOCIAL”}

O fenômeno social não é aqui considerado como análogo ao tipo ideal weberiano. Entende-se por fenômeno social a conformação objetiva de uma dada realidade, resultante direta de um contexto específico das relações estabelecidas social e historicamente. Segundo Tckeskiss (1922, s/p.) "[...] cada fenômeno social tem de estar ligado aos esforços que forjam a sociedade, isto é, aos homens e os fenômenos sociais devem, portanto, ser o resultado da atividade humana, que, como tal está relacionado com a consciência humana". Para o autor, a complexidade de compreensão dos fenômenos sociais encontra-se justamente na dificuldade de se estabelecer limites entre suas dimensões sociais e suas dimensões subjetivas/objetivas individuais. Portanto, é preciso entender que os fenômenos sociais se desdobram em seu caráter subjetivo/objetivo, podendo ora apresentarem-se como tipicamente circunscritos no metabolismo social, ora como tipicamente resultantes dos processos de subjetivação.

Considere, por exemplo, o suicídio. Enquanto fenômeno social, foi tema amplamente abordado pela sociologia, com atenção especial para Durkheim (2000), em sua obra "O Suicídio". Seu estudo figura como interesse intelectual a partir do momento em que passa a ser considerado um fenômeno social negativo, ou seja, a ser compreendido por um grupo de pessoas como prejudicial a um determinado grupo de sujeitos, comunidade ou para a sociedade como um todo. Por isso, é preciso compreender que os fenômenos sociais, no sentido amplo do termo, podem ser positivos ou negativos. Sua principal característica, então, é ser resultado da relação objetiva entre os sujeitos. Pensando no exemplo citado, pode-se perceber que as interpretações frequentemente podem oscilar entre explicações causais subjetivas-idealistas (problemas exclusivamente psicológicos dos sujeitos), funcionalistas (a sociedade condiciona o sujeito ao sofrimento e ao suicídio) ou dialéticas (subjetivo/objetivo estão em relação e, em razão disso, o fenômeno possui imbricada as duas dimensões). Assumimos como mais coerente essa última concepção, por compreender que é a forma material como a sociedade se organiza que determina as condições subjetivas e objetivas de sua existência.

Se o fenômeno social é o objeto do "trabalho social", duas questões precisam ser respondidas: primeiro, como esse conceito se deslocou historicamente diante dos distintos modelos de extensão rural? Segundo, como se relaciona com as atribuições específicas de cada profissional da "área social" na ATER?

Se retomamos ao período de implantação da extensão rural no Brasil, na década de 1950, é fácil compreender qual fenômeno social norteava as ações de ATER. Rodrigues 
(1997), Lopes (1995), Fonseca (1985) e Pinheiro (2016) demonstraram certo consenso em estabelecer que a base sobre a qual se erigiu a prática extensionista brasileira era a noção amplamente difundida de existência de um campo atrasado econômica, produtiva e culturalmente. Logo, o fenômeno social geral era o "atraso no campo", mesmo que sua leitura e interpretação geral tivesse elementos etnocêntricos e equivocados resultantes de uma inadequada compreensão da relação aparência-essência do fenômeno em si, tal como apresenta Oliveira (2013). Tendo em vista tal leitura, a prática também estava bastante estabelecida para a área social: promover mudanças de hábitos e comportamentos, sobretudo no ambiente doméstico e na esfera "familiar" considerado lócus desse profissional. Por isso, o profissional de Economia Doméstica se apresentou, nesse primeiro momento, como ideologicamente alinhado aos princípios gerais da extensão rural (PINHEIRO, 2016). Apesar das inúmeras críticas ao modelo de atuação proposto, não se pode negar que essa extensão promoveu mudanças positivas, como melhoria nos hábitos alimentares e de higiene da população do campo (LOPES, 1995).

Já no período do difusionismo-produtivista, que prevaleceu nas décadas de 1960, 1970 e 1980, o fenômeno social que norteava o trabalho da extensão rural se modificou de tal forma que passou a contemplar raramente um escopo para a área social. Isso porque seu recorte estava baseado em uma leitura da realidade ancorada na "produção agrícola ineficiente e de produtos com baixo valor de mercado" (PEIXOTO, 2008), fenômeno que abraçava dimensões puramente tecnológicas e produtivas, contemplando apenas muito tangencialmente algumas ponderações sociais. Não ocasionalmente, nessa época, o foco da extensão passou a ser a difusão de tecnologias e o estímulo às commodities e a área social, reduzida ora a fragmentos do modelo anterior, ora a ações pontuais de complementariedade às ações produtivistas. É nesse período, também, que parece ter ganhado força o modelo da área social voltado à geração de trabalho e renda e às analogias das casas e propriedades rurais com pequenas empresas capitalistas. Mas, no geral, a área social tendeu a ficar em uma relação de subsunção às pautas produtivistas pela forma como o fenômeno social estava posto à extensão rural dessa época.

A situação de efervescência dos anos 1980, descrita por Peixoto (2008) como de intenso debate em torno da ATER e das pautas dos movimentos sociais, que se estenderiam por toda a década de 1990 e provocariam mudanças significativas no escopo de trabalho, foi responsável também por modificar, sobremaneira, o fenômeno social a partir do qual a ATER pública oficial se orientaria. Primeiro, porque, embora o modelo difusionista-produtivista tenha gerado bons e importantes resultados nas décadas anteriores, os efeitos sociais perversos que 
subjazem à sua própria lógica colocaram importantes demandas no debate público. As limitações econômicas em períodos de crise das commodities, a segurança na produção segundo inclusão de novas tecnologias e defensivos agrícolas, o estrangulamento das pequenas propriedades com consequente êxodo, o aumento de um exército de reserva no campo, dentre outros eventos podem ser citados como exemplos dessas pautas que emergiram (PEIXOTO, 2008).

Dessa maneira, o intenso debate em torno de superar o modelo posto desde a década de 1960 em consonância com a redemocratização do país e a emergência de um governo neoliberal resultaram em um cenário contraditório, no qual a extensão rural, ao passo que buscou legitimar um novo modelo, humanista crítico, pautado em outros objetivos, públicos e ações, viu-se constantemente ameaçada e enfraquecida. Sepulcri e Paula (2008) demonstram como a extinção da EMBRATER no início dos anos 1990 representou um corte orçamentário de quase $40 \%$ dos recursos do EMATER-PR, colocando urgência na pactuação de projetos que garantissem certa continuidade nas ações institucionais.

De forma geral, esse momento de reorientação se baseou em outro fenômeno social, priorizando a emergência da categoria "agricultor familiar" e incorporando os elementos da crítica ao modelo difusionista-produtivista. Assim, a ATER, a partir da década de 1990, passou a se orientar - pelo menos formalmente - segundo um fenômeno social de múltiplas dimensões: a PNATER expõe desde a redução das desigualdades no campo, perpassando a promoção de equidade de gênero, valorização das culturas locais e inclusão social, até a transição produtiva para formas mais sustentáveis de produção (BRASIL, 2010).

Essa transição ocorreu, desse modo, de um fenômeno social restrito na esfera desenvolvimentista, etnocentrado e com orientação moralista-higienista (humanismo assistencialista), para um fenômeno especificamente economicista/produtivista/tecnicista (difusionismo-produtivista), assumindo a partir da década de 1990 uma conformação difusa, marcada pelo agrupamento de diversos outros fenômenos sociais em suas variadas formas de manifestação no campo (humanismo crítico - em suas tentativas de implantação). Todavia, essa transição, longe de ser etapista, precisa ser compreendida dialeticamente na complexidade das relações entre os agentes pedagógicos que a efetivaram e os materiais e rituais pedagógicos que estruturam suas práticas. Uma análise específica de como essa articulação histórica se estabeleceu no estado do Paraná auxiliará a ilustrar o problema apresentado. 


\section{FRAGMENTOS E INVERSÕES: O CASO DA ATER PARANAENSE}

Antes de prosseguirmos com a análise prática, é necessário pontuarmos sobre como essas profissões (Economia Doméstica e Serviço Social) se articulam com o fenômeno social posto para a extensão rural a partir da década de 1990. Mesmo que o discurso da categoria seja permeado por elementos unificadores em torno do termo "extensionista", subentende-se que, por exigência em edital de concurso público, formações específicas e com atuação regulamentada por conselhos, há a demanda institucional por habilidades determinadas relacionadas a certos campos do saber/agir profissional.

Pensando nos fenômenos sociais a partir dos quais as formações específicas exigidas para área social se orientam, há dois cenários bastante delimitados: em primeiro lugar, é amplamente discutido, no bojo da formação em Serviço Social, que a profissão tem um projeto ético-político em defesa da classe trabalhadora, atuando sobre as expressões da Questão Social, ou seja, sobre os efeitos adversos e as potencialidades oriundas do metabolismo do capital (IAMAMOTO, 1992). Nesse prisma, o profissional é preconizado para atuar nas esferas público e privada tendo como perspectiva os fenômenos sociais que decorrem dessa relação. Em segundo lugar, de forma mais genérica, a Economia Doméstica se posiciona como uma formação e profissão que busca melhorar a qualidade de vida das famílias em suas atividades e ambiente doméstico (AMARAL JUNIOR, 2016). Seu objeto "oficial" tem sido historicamente a família, embora na realidade tenha sempre priorizado as mulheres, as atividades domésticas por elas executadas e certa normatização desse universo (AMARAL JUNIOR; ALVES, 2019).

Embora esses sejam os fenômenos sociais sobre os quais as duas formações dizem se orientar atualmente, é sabido que, objetivamente, a gênese de cada uma delas aponta para posições mais ou menos próximas. O Serviço Social - bem mais consciente e compromissado com sua própria trajetória - emergiu no final do século XIX enquanto prática no bojo de uma percepção higienista, reformadora para o trabalho, moralista cristã e alinhada aos interesses do capitalismo (CASTRO, 2011). Sabe-se que há duas teses divergentes para a gênese do Serviço Social ${ }^{11}$, mas assumimos aqui como mais adequada aquela que se afasta da corrente endógena e relaciona o surgimento da profissão/área com o contexto social e histórico do agravamento dos efeitos do capitalismo, aguçamento da função do Estado e gerenciamento da burguesia sobre as expressões da Questão Social. A Economia Doméstica, de forma análoga, também emergiu enquanto disciplinadora para posições sociais vocacionalmente estabelecidas entre homens e mulheres, com uma percepção higienista, moralista-cristã e normatizadora

${ }^{11}$ Conforme também demonstra Castro (2011) em "História do Serviço Social na América Latina". 
alinhada aos interesses do capitalismo, também no século XIX, com forte institucionalização no século XX (AMARAL JUNIOR; ALVES, 2019). Dessa maneira, ainda que as profissões/áreas de conhecimento tenham surgido enquanto resposta a uma demanda bastante comum, afastaram-se historicamente em torno daquilo que delimitaram enquanto seus objetos. Essa diferenciação está expressa, mesmo que de forma pouco demarcada, nos perfis profissiográficos do EMATER-PR que foram anteriormente analisados.

Isso quer dizer que, embora historicamente as duas profissões estejam bem próximas, no final do século XX se reorientaram para uma gama de fenômenos sociais bastante diversos os quais, ainda que possam se encontrar e sobrepor em certas situações, indicam recortes diferenciados. A Economia Doméstica se debruça sobre fenômenos de origem mais micro, ligados ao bem-estar imediato dos sujeitos no ambiente doméstico e, mesmo pleiteando uma visão holística, não possui arcabouço teórico-metodológico para sustentá-lo, além da formação tecnicista/positivista que prevalece desde a década de 1950 (AMARAL JUNIOR, 2016). Vale ressaltar que a Economia Doméstica implantada no Brasil trazia marcas de certo hibridismo de seu modelo estadunidense que, à época - década de 1950 -, já se encontrava em pleno declínio (AMARAL JUNIOR; ALVES, 2019).

Já o Serviço Social, mobilizado por um projeto ético-político ${ }^{12}$, localiza-se no centro das contradições da luta de classes, marcando como objeto de sua intervenção os fenômenos sociais mais amplos decorrentes desse movimento e, embora legisle pela competência em lidar com aspectos mais micro, raramente consegue sustentar-se também nessa empreitada. Considerando a orientação de cada formação, é possível perceber um cenário de possibilidade de complementariedade, mas raramente um cenário de orientação ao mesmo fenômeno social, segundo atribuições e métodos de intervenção similares.

Apesar disso, a Economia Doméstica tem sido mais aproximada, nas últimas décadas, do objeto do Serviço Social do que das ciências econômicas - como o senso comum frequentemente costuma designar - ou das ciências biológicas, como Ribeiro (2010) descreve ter sido o escopo predominante da implantação dos cursos superiores da área no Brasil. $\mathrm{O}$ único curso de Pós-Graduação no nível de mestrado e doutorado em Economia Doméstica no país está classificado pela Coordenação de Aperfeiçoamento de Pessoal de Nível Superior (CAPES) na grande área de Serviço Social e, além disso, dois Departamentos de Economia Doméstica - da UFRRJ e da UFV - passaram a ofertar o bacharelado em Serviço Social a partir da infraestrutura física e docente existente após o encerramento de ingresso para o curso de Economia Doméstica. Mesmo com essas evidências, têm sido escassos os trabalhos que

\footnotetext{
${ }^{12}$ Para aprofundamento do Projeto Ético-Político do Serviço Social, ver Teixeira e Braz (2009).
} 
pretendem analisar as proximidades entre as duas áreas e, no que se refere à delimitação de seus objetos, essa proximidade parece, provisoriamente, muito superficial.

Retomando a análise, estudando especificamente cada um dos marcos legais que orientam as ações de extensão no estado do Paraná, é possível perceber, a partir dos elementos expostos, quais são os fenômenos sociais que se apresentam como urgentes para o "trabalho social" de ATER. Esses fenômenos devem compor a base do trabalho da área social, sendo distribuídos no nível operacional segundo as atribuições específicas dos profissionais que compõem sua equipe. Foram considerados para análise apenas as partes constituintes dos problemas e ações apresentados que concernem ao objeto da área social - ações e objetivos explicitamente de abordagem produtiva, como, por exemplo, a transição para cultivo de orgânicos, foram considerados ancorados em fenômenos restritos à área produtiva/econômica. Foram consultadas a Política Estadual de Assistência Técnica e Extensão Rural - PEATER (PARANÁ, 2012)), o Plano de Governo Macro Centro-Sul, disponibilizado no site da Secretaria Estadual de Agricultura e Abastecimento (SEAB) e as Diretrizes Institucionais e os papeis Institucionais do EMATER-PR, disponíveis na homepage da instituição. Uma sistematização desses fenômenos está apresentada no Quadro 1.

Quadro 1 - Sistematização dos principais fenômenos sociais identificados nos documentos regulamentadores da ATER paranaense

\begin{tabular}{|c|c|c|c|}
\hline PEATER & $\begin{array}{l}\text { Plano de Governo } \\
\text { (Macro Centro-Sul) }\end{array}$ & $\begin{array}{c}\text { Diretrizes } \\
\text { Institucionais } 2019\end{array}$ & $\begin{array}{c}\text { Papeis } \\
\text { institucionais }\end{array}$ \\
\hline $\begin{array}{l}\text { Desigualdade social } \\
\text { no campo; } \\
\text { Existência de } \\
\text { condições de vida } \\
\text { precárias no campo; } \\
\text { Existência de } \\
\text { metodologias } \\
\text { diretivas na prática } \\
\text { de ATER; } \\
\text { Baixo conhecimento } \\
\text { e acesso às } \\
\text { Políticas Públicas } \\
\text { pela população do } \\
\text { campo; } \\
\text { Desvalorização das } \\
\text { culturas, modos de } \\
\text { vida e fazeres do } \\
\text { campo. }\end{array}$ & $\begin{array}{l}\text { Existência de parcela } \\
\text { da população excluída } \\
\text { socialmente; } \\
\text { População do campo } \\
\text { que, em partes, vive } \\
\text { em condições } \\
\text { precárias; } \\
\text { Ausência de acesso } \\
\text { aos serviços básicos } \\
\text { por parte da } \\
\text { população do campo; } \\
\text { Condições precárias } \\
\text { de segurança } \\
\text { alimentar e nutricional; } \\
\text { Parte da população } \\
\text { sobrevivendo com } \\
\text { baixos rendimentos e } \\
\text { em situação precária } \\
\text { de trabalho. }\end{array}$ & $\begin{array}{l}\text { Parcela da população } \\
\text { excluída socialmente e } \\
\text { dos processos } \\
\text { produtivos; } \\
\text { Existência de } \\
\text { desequilíbrios } \\
\text { regionais; } \\
\text { Exxodo; } \\
\text { Pauperização do } \\
\text { campo. }\end{array}$ & $\begin{array}{l}\text { Ausência de acesso, } \\
\text { por parte da } \\
\text { população do campo, } \\
\text { às Políticas Públicas; } \\
\text { Necessidade de } \\
\text { estruturar e colocar } \\
\text { em prática o Plano de } \\
\text { ATER. }\end{array}$ \\
\hline
\end{tabular}

Fonte: Dados da Pesquisa (2019). 
Pode-se perceber que a PEATER está alinhada com muitos dos elementos dispostos na PNATER, elencando uma série de fenômenos sociais distintos. Já as Diretrizes Institucionais do EMATER-PR e seus papeis institucionais demonstram um recorte mais preciso, apresentando uma gama mais limitada de fenômenos sobre os quais os profissionais da área social devem se debruçar a partir da realidade paranaense.

Entretanto, sabe-se que o fenômeno social não é, em si mesmo, a definição do trabalho, mas a parcela da realidade objetiva para a qual os esforços desse trabalho devem ser orientados, para fins de compreensão, intervenção e transformação. Esses fenômenos apenas se apresentam como a base para erigir o planejamento de trabalho, que deve ser operacionalizado segundo uma orientação metodológica e um cabedal instrumental.

O primeiro problema que disso decorre vem da baixa reflexão metodológica e de sua adequada conexão com um aporte instrumental adequado. Guimarães e Silva (2012), ao apresentarem as tendências pedagógicas historicamente adotadas pelo EMATER-PR, intentam demonstrar como o campo do debate se manteve aquecido, sobretudo a partir dos anos 1980, na busca enquanto uma instituição de educação não formal por aportes teóricos pedagógicos que conseguissem subsidiar uma prática de trabalho coerente e eficaz. Os autores argumentam, inclusive, por uma virada nesse aporte em meados de 2007, época a partir da qual os pressupostos da Pedagogia Histórico-Crítica ${ }^{13}$ passaram a figurar como prioridade nesse empreendimento. No entanto, há carências de evidências que consigam sustentar que essa guinada teórico-metodológico de fato tenha ocorrido.

Um documento construído em 2010 pela Agência Nacional de Assistência Técnica e Extensão Rural - ANATER (BRASIL, 2010) propõe fazer um esforço similar, em um resultado intitulado "Fundamentos teóricos, orientações e procedimentos metodológicos para a construção de uma pedagogia de ATER". No documento, prioriza-se novamente a discussão em torno dos elementos pedagógicos que subsidiam a prática de ATER, valendo-se das contribuições de autores como Piaget, Vygotsky, Freire e Castoriadis. A publicação avança sobremaneira ao estabelecer diretrizes básicas ao trabalho de ATER que se alinham ao proposto na PNATER, indicando certa coerência entre o que se pode considerar um "método em extensão rural" diante do fenômeno social a partir do qual ela passou a se estruturar pós anos 1980. Contudo, a fundamentação se dilui no hibridismo teórico, perdendo solidez metodológica ao mesclar correntes epistemologicamente opostas que, na prática, interpretam o

\footnotetext{
${ }^{13}$ A Pedagogia Histórico-Crítica é uma proposta construída por Demerval Saviani a partir dos pressupostos do materialismo histórico-dialético.
} 
mundo e os fenômenos sociais de formas antagônicas e conflitantes. Além disso, o escopo instrumental fica novamente de fora do campo do debate, abrindo espaço para que diretrizes metodologicamente mais ou menos renovadas percam força diante de um cabedal instrumental conservador. Além disso, assumir que o EMATER-PR aderiu às orientações metodológicas dispostas no documento da ANATER é, por consequência, entender que abandonou um projeto em torno dos pressupostos da Pedagogia Histórico-Crítica, como defendem Guimarães e Silva (2012). Isso porque Saviani (2005), principal referência dessa proposta pedagógica, demonstra-se contrário aos pressupostos freireanos, designando-os como uma tipologia do escolanovismo, adaptada à educação popular, e inadequados à possibilidade crítica de mudança do processo educativo.

Essa digressão em torno do método e do aporte instrumental demonstra como o cenário para a área social se complicou expressivamente, na medida em que ora se pauta em um debate teórico-metodológico contraditório e inacabado, ora se vale dos aportes metodológicos e instrumentais da área produtiva que, vale ressaltar, possui outros elementos teóricometodológicos prevalentes, como o método experimental. Demonstra como o desafio está posto em tentar fomentar um "método de ATER" para áreas e formações profissionais que possuem objetos e orientação a fenômenos sociais diversos e, por isso, não podem estar englobadas segundo um mesmo aporte teórico-metodológico generalista.

Esse problema, longe de ser um contexto isolado do estado do Paraná, reflete a extensão brasileira como um todo. Landini (2015) demonstra como o difusionismo ainda é prevalente nas práticas extensionistas, limitando a percepção dos profissionais em relação ao seu objeto e campo de intervenção, consequentemente, trazendo reflexos metodológicos de ordens diversas - como o autor destaca, por exemplo, a manutenção de uma intervenção diretiva pautada no "agricultor problema". As mudanças pós década de 1990, por sua vez, colocaram sérios limites ao difusionismo, demandando uma extensão que se fizesse obrigatoriamente interdisciplinar em abordagem e método, mas que ainda não almejou tal status (FAVERO; SERRIERA, 2009).

Para a área social, isso significa dizer que Assistentes Sociais e Economistas Domésticos, como principais representantes dessa frente de trabalho ${ }^{14}$, não encontram um método uníssono para o trabalho na extensão rural, tampouco um conjunto instrumental a partir do qual podem planejar suas ações. Na realidade, deparam-se com fragmentos mais ou menos

\footnotetext{
${ }^{14}$ Desde os primórdios da extensão rural, a área de bem-estar social absorveu uma gama diversificada de profissionais, como assistentes sociais, pedagogos e cientistas sociais. No entanto, reitera-se o exposto por Pinheiro (2016), demarcando assim uma alta prevalência dos economistas domésticos durante os anos 19501960, seguindo, apenas mais tarde, para uma diversificação mais abrangente.
} 
estabelecidos, cuja maioria pende à discussão pedagógica em seus termos gerais, mas raramente descendem às formas de efetivação das ideias pedagógicas, às contradições dos distintos agentes pedagógicos imbuídos no processo e às inadaptabilidades dos materiais e rituais pedagógicos mobilizados.

Então como, diante desse cenário, a área social parece lidar com os fenômenos sociais apresentados enquanto base de seu trabalho? Analisando o Relatório de Atividades do EMATER-PR de 2017/2018, algumas evidências podem ser destacadas. A maior delas talvez seja a ausência de menção a essa divisão entre os fenômenos sobre os quais se debruçam os profissionais da área produtiva e aqueles que pautam o trabalho dos profissionais da área social. Além disso, a descrição das atividades - se analisadas em conjunto com outros elementos institucionais disponibilizados pelo Instituto em sua homepage oficial - parece indicar que, especificamente para o trabalho designado aos profissionais da área social, há uma inversão no processo de compreensão e intervenção da realidade.

Conforme abordado anteriormente, o fenômeno social é aquele fragmento da realidade que corresponde a uma dimensão macro, geralmente apresentada de forma negativa, para que se possa solucionar/mitigar/compensar ou de forma positiva, para que se possa maximizar/incentivar. Seriam exemplos o êxodo rural acelerado e as dificuldades de se estabelecer os processos de sucessão familiar no campo, para o primeiro caso, e o maior envolvimento das mulheres nas tomadas de decisão familiares e integração dos jovens aos movimentos populares do campo, para o segundo. $O$ fenômeno social não pode ser apreendido apenas pela percepção de um sujeito, mas deve encontrar validação na objetividade, nos dados estatísticos e na empiria de diversos sujeitos imbuídos no processo.

Uma vez identificado o fenômeno social, é preciso estabelecer estratégias de ação que irão compor o eixo estruturante para a modificação almejada. Essas estratégias devem agrupar as diretrizes norteadoras da ação, mas não se confundem com o ato em si. Por exemplo, se o fenômeno social que se apresenta é o assalariamento dos trabalhadores do campo, há algumas linhas de estratégias possíveis. Suponhamos duas delas: (i) em uma das linhas, podese pretender reverter essa situação com parte da família, introduzindo uma série de ações que estimulem o retorno dos sujeitos assalariados para a condição de agricultores familiares produtores diretos; e (ii) em outra das linhas, para aqueles sujeitos e famílias que não se adequem à primeira, pode ser possível pensar uma série de ações que visem ampará-los e assessorá-los frente à situação de assalariamento. A definição de quais profissionais se orientarão em cada caso dependeria, portanto, da inclinação de seus objetos: pode-se pensar, assim, nos economistas domésticos mais orientados às ações que remetam ao cotidiano 
familiar e às dinâmicas da economia familiar, enquanto os assistentes sociais podem incidir sobre uma prática da garantia de direitos, articulação com as políticas sociais e mobilização social.

As ações, por sua vez, decorrem das formas de operacionalizar cada uma das estratégias elencadas. Para a linha I, por exemplo, pode-se investir em uma série de eventos, cursos, visitas técnicas e atividades de assistência técnica que ajudem a promover esse "retorno" às famílias. Para a linha II, pode-se pensar em ações similares com conteúdos de ergonomia, previdência social, proteção social. Pensar as atividades de extensão rural dentro desse contexto requer seguir certa estrutura de operacionalização que coloque as ações em dependência das estratégias, para responder aos fenômenos sociais identificados. Um esquema desse modelo está apresentado na Figura 1.

Figura 1 - Estrutura de operacionalização do trabalho social segundo identificação dos fenômenos sociais

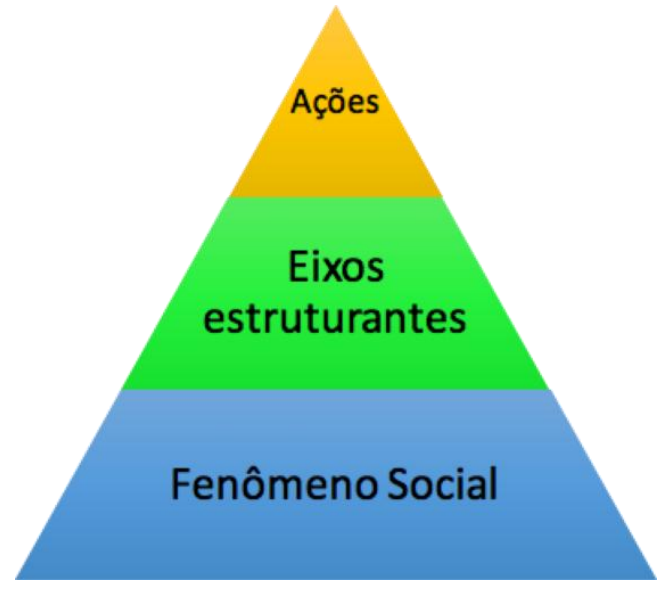

Fonte: Elaborado pelo autor

Ao que parece, analisando-se os documentos institucionais, predomina uma inversão desse modelo, em que as ações frequentemente aparecem como norteadoras do trabalho, em alguns poucos casos, mencionando-se eixos estruturantes que as designam, mas raramente apontando o fenômeno social que orienta a intervenção do extensionista. O Relatório de Atividades (EMATER, 2019) apresenta as ações por públicos específicos (como indígenas e quilombolas) e por conjunto temático (como turismo rural e agroindústria). Em alguns desses casos, faz menção ao eixo estruturante que impulsiona a ação - por exemplo, o turismo rural é justificado enquanto estratégia de geração de trabalho e renda e dinamização das economias locais. 
Sabe-se, no entanto, que uma gama bastante variada de atividades pode impulsionar ações de geração de trabalho e renda e que apenas elas, isoladamente, serão incapazes de promover transformações significativas em quaisquer que sejam os fenômenos sociais de origem. Ao apresentar as atividades nesse modelo, sem relacioná-las aos fenômenos sociais comuns ou distintos, opera-se uma inversão ideológica da intervenção social, em que a ação aparece como o fim em si mesmo, tornando-se frequente tomar as consequências como objetivos e ocultando o fenômeno social que deveria ser a base de todo o planejamento interventivo. Um modelo dessa inversão é apresentado na Figura 2.

\section{Figura 2 - Estruturação aparente do trabalho da área social da ATER paranaense}

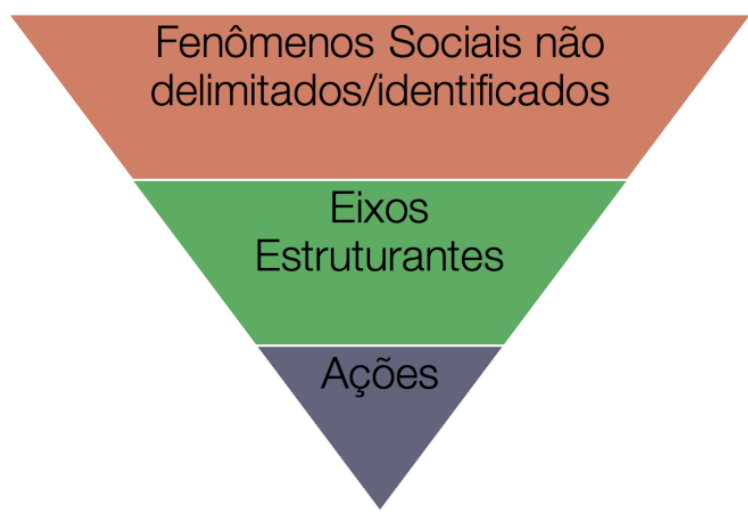

Fonte: Elaborado pelo autor

Essa inversão, hipoteticamente, pode beneficiar os Economistas Domésticos cujo cabedal instrumental tecnicista está muito mais próximo da intervenção imediata e das ações concretas do que os Assistentes Sociais, cujos fenômenos sociais de origem estão ancorados em uma noção mais ampla das relações sociais. De qualquer forma, demonstra como os fenômenos sociais implícitos na PNATER se diluem na prática do extensionista social do EMATER-PR, ganhando pouca objetividade nas ações de planejamento e se perdendo em um conjunto de ações que não possuem correspondentes teórico-metodológicos delimitados, mas uma ampla herança nos modelos históricos pretéritos de extensão rural.

\section{CONSIDERAÇÕES FINAIS}

O problema se apresenta, ainda, como uma questão em aberto, na medida em que a própria noção de ATER do século XXI carrega certo hibridismo herdado de seus distintos modelos históricos os quais, consequentemente, resultam na coexistência de práticas diversas. Ao se considerar o recorte pretendido para a "área social", o interesse pela sua constituição 
dentro da extensão rural sempre foi secundário, cenário que tende a mudar, segundo as discussões e políticas mais recentes que tangenciam ou envolvem a prática de ATER e redirecionam as políticas agrárias para um outro público - o agricultor familiar - sob uma outra perspectiva.

Pode-se concluir, em primeiro lugar, que a trajetória histórica de constituição da área social no Instituto EMATER-PR contribuiu para que fosse promovido um afastamento entre as ações desses profissionais e a clareza de orientação em torno de determinados fenômenos sociais. De forma complexa, esse afastamento se operou segundo os modelos distintos pelos quais passou a extensão rural, de acordo com as mudanças estruturais das próprias profissões que compõem o quadro da área e segundo a ausência de uma reflexão teórico-metodológica, no bojo da ATER, que fosse capaz de unificar os elementos e considerar as diferenças próprias das áreas disciplinares e das formações específicas.

Embora os elementos de análise ainda sejam escassos, analisando os documentos públicos mais recentes que descrevem as atividades da instituição, é possível perceber alguns pontos centrais: uma inversão ideológica, em que a operacionalização se sobrepõe à análise do objeto da intervenção (os fenômenos sociais); um debate teórico-metodológico que avançou em seus elementos pedagógicos, estagnou na noção de instrumentalização e pouco se manifestou na descrição da prática do método; e uma composição de ação da área social ainda baseada em fragmentos de modelos anteriores que se pautavam, por sua vez, em outros fenômenos sociais que não são postos hoje como prioridades da PNATER, Política Pública que orienta e regulamenta - pelo menos em teoria - a ação extensionista no país.

A atuação dos economistas domésticos e assistentes sociais, nesse contexto, parece fragmentada, sobreposta e pouco estruturada. Com a reorientação das ações de ATER das últimas duas décadas, a extensão rural se aproximou das políticas sociais voltadas à população do campo, impulsionando a diversificação das equipes extensionistas. Assim, os objetos de intervenção da Economia Doméstica e do Serviço Social se diluem em técnicas préestabelecidas e em ações pontuais que colocam em segundo plano os fenômenos sociais sobre os quais atuam, sombreando, por sua vez, as possibilidades mais claras de delimitação entre ambas as formações. Há que se considerar, ainda, que, enquanto campo profissional regulamentado, a Economia Doméstica caminha para um lento processo de extinção, visto que não há mais novos profissionais ingressando no mercado de trabalho com o fechamento oficial de todos os cursos da área ofertados no país. A situação peculiar com a qual a extensão rural ainda terá de lidar, ao que tudo indica, é a de definir o escopo de trabalho e a orientação daquela que parece ser a última geração de economistas domésticos extensionistas. Com 
relação aos assistentes sociais, um processo inverso parece ser necessário: definir melhor o campo de atuação desse profissional que, embora não seja recente sua inclusão nas equipes de ATER, tem visto seu espaço aumentar em função da demanda cada vez mais próxima observada entre políticas agrárias e políticas sociais.

O desafio que se coloca, portanto, para a área social, é estabelecer um amplo diálogo teórico-metodológico que permita superar essa inversão, construir instrumentais coerentes com os objetos de cada formação e área disciplinar e delimitar contextualmente os fenômenos sociais para os quais orientam seus esforços coletivos de intervenção e transformação.

\section{REFERÊNCIAS}

AMARAL JUNIOR, José Carlos do. Economia Doméstica: adaptação, transformação ou extinção? 2. ed. São Paulo: PerSe, 2016.

AMARAL JUNIOR, José Carlos do; ALVES, Ana Elizabeth dos Santos. Economia Doméstica, extensão rural e a categoria família: mascaramento ideológico e reprodução da lógica do capitalismo em uma Política de Estado. [em construção], 2019.

ANDRADES, Tiago Oliveira de; GANIMI, Rosângela Nasser. Revolução Verde e a apropriação capitalista. CES Revista, v.21, p. 43-56, 2007.

BRASIL. Fundamentos Teóricos, orientações e procedimentos metodológicos para a construção de uma pedagogia de ATER. 2010.

BRASIL. Lei $\mathbf{n}^{\circ} \mathbf{1 2 . 1 8 8}$ de 11 de janeiro de 2010. Institui a Política Nacional de Assistência Técnica e Extensão Rural para a Agricultura Familiar e Reforma Agrária PNATER e o Programa Nacional de Assistência Técnica e Extensão Rural na Agricultura Familiar e na Reforma Agrária PRONATER, altera a Lei no 8.666, de 21 de junho de 1993, e dá outras providências. Disponível em: <http://www.planalto.gov.br/ccivil 03/ ato2007-

2010/2010/lei//12188.htm> acesso em 20 de setembro de 2019.

CAPORAL, Francisco Roberto. A extensão rural e os limites à prática dos extensionistas do serviço público. 1991. Dissertação (Mestrado em Extensão Rural) - Universidade Federal de Santa Maria, Santa Maria-RS, 1991.

CASTRO, Manuel Manrique. História do Serviço Social na América Latina. 12. ed. São Paulo: Cortez, 2011.

CURY, Carlos Roberto Jammil. Educação e contradição. 2. ed. São Paulo: Cortez, 1989.

DURKHEIM, Emile. O suicídio. São Paulo: Martins Fontes, 2000.

EMATER-PR. Relatório de Atividades 2017-2018. 2019. Disponível em: http://www.emater.pr.gov.br/arquivos/File/Institucional/EMATER RelAtiv2017 18.pdf. Acesso em: 10 jun. 2019. 
FAVERO, Eveline; SERRIELA, Jorge Castellá. Extensão Rural e intervenção: velhas questões e novos desafios para os profissionais. Cadernos de Psicologia Social do Trabalho, v. 12, n. 1, p. 1-16, 2009.

FONSECA, Maria Teresa Lousa. A extensão rural no Brasil, um projeto educativo para o capital. São Paulo: Edições Loyola, 1985.

FREIRE, Paulo. Extensão ou comunicação? 19. ed. Rio de Janeiro: Paz e Terra, 2018.

GIL, Antônio Carlos. Métodos e técnicas de pesquisa social. 4. ed. São Paulo: Atlas, 1994.

GOHN, Maria da Glória. Educação não-formal, participação da sociedade civil e estruturas colegiadas nas escolas. Ensaio: avaliação de políticas públicas educacionais, v. 14, n. 50 , p. 27-38, 2006.

GUIMARÃES, Roberto Carlos.; SILVA, Adnilson José. Tendências político-pedagógicas na Assistência Técnica Oficial do Paraná. 2012. Trabalho de Conclusão de Curso (Especialização) - Programa de Pós-Graduação em Metodologias Participativas e Fundamentos Político-pedagógicos para a Assistência Técnica e Extensão Rural, Universidade Estadual do Centro do Paraná, Guarapuava-PR, 2012.

IAMAMOTO, Marilda. Servicio Social y division del trabajo. 2. ed. São Paulo: Cortez, 1992.

LANDINI, Fernando Pablo. Problemas enfrentados por extensionistas rurais e suas relações com as concepções de extensão rural. Ciência Rural, v. 45, n. 2, p. 371-377, 2015.

LOPES, Maria de Fátima. O Sorriso da Paineira: construção de gênero em uma Universidade Rural. 1995. Tese (Doutorado em Antropologia Social) - Museu Nacional, Universidade Federal do Rio de Janeiro, Rio de Janeiro, 1995.

MARX, Karl; ENGELS, Firederich. A ideologia Alemã. São Paulo: Boitempo, 2007.

NETTO, José Paulo. Introdução ao estudo do método em Marx. São Paulo: Expressão Popular, 2011.

OLIVEIRA, Pedro Cassiano Farias de. Extensão rural e interesses patronais no Brasil: uma análise da Associação Brasileira de Crédito e Assistência Rural - ABCAR (1948-1974). 2013. Dissertação (Mestrado em História) - Universidade Federal Fluminense, Niterói-RJ, 2013.

PARANÁ, GOVERNO DO ESTADO. Secretaria de Administração e Previdência. Edital $\mathbf{n}^{\circ}$ 079/2014. 2014a.

PARANÁ, GOVERNO DO ESTADO. Lei no 17.447 de 27 de dezembro de 2012. Institui a Política Estadual de Assistência Técnica e Extensão Rural (PEATER-PR) e o Programa Estadual de Assistência Técnica e Extensão Rural (PROATER-PR). Curitiba-PR, 2012. Disponível em: <http://www.emater.pr.gov.br/modules/conteudo/conteudo.php?conteudo=89> acesso em 20 de setembro de 2019.

PARANÁ, GOVERNO DO ESTADO. Edital n ${ }^{\circ}$ 116/2014. 2014b. Disponível em: <http://www.cops.uel.br/concursos/177 seap emater/edital 116 2014.pdf> Acesso em: 20 set. 2019. 
PEIXOTO, Marcos. Extensão rural no Brasil - uma abordagem histórica da legislação. Textos para Discussão - Senado Federal, 2008. Disponível em: <

https://www12.senado.leg.br/publicacoes/estudos-legislativos/tipos-de-estudos/textos-para-

discussao/td-48-extensao-rural-no-brasil-uma-abordagem-historica-da-legislacao > acesso em 15 de agosto de 2019.

PINHEIRO, Camila Fernandes. Estado, extensão rural e economia doméstica no Brasil (1948-1974). 2016. Dissertação (Mestrado em História) - Universidade Federal Fluminense, Niterói-RJ, 2016.

RIBEIRO, Maria das Graças. A constituição das ciências humanas numa Universidade Rural. ALEPH, v. 14, p. 52-60, 2010.

RODRIGUES, Cyro Mascarenhas. Conceito de seletividade de políticas públicas e sua aplicação no contexto da política de extensão rural no Brasil. Cadernos de Ciências e Tecnologia, v. 14, n. 1, 1997.

SAVIANI, Demerval. As concepções pedagógicas na história da educação brasileira. In: Projeto 20 anos do HISTEDBR. Campinas, SP: [s.n.], 2005.

SEPULCRI, Odílio; PAULA, Nilson Maciel de. O Estado e seus impactos na EMATER-PR. Revista Paranaense de Desenvolvimento, n. 114, p. 87-110, 2008.

TCKESKISS, L. A. O Materialismo Histórico em 14 lições. In: Universidade Comunista para as minorias nacionais do Ocidente. [s.I.: s.n.], 1922. Disponível em: https://www.marxists.org/portugues/tematica/1922/materia/index.htm. Acesso em: 20 out. 2019.

TEIXEIRA, Joaquina Barata; BRAZ, Marcelo. O. O projeto ético-político do Serviço Social. CFESS/ABEPSS. 2009. Disponível em: <http://www.abepss.org.br/arquivos/anexos/teixeirajoaquina-barata -braz-marcelo-201608060407431902860.pdf> acesso em 12 de setembro de 2019. 